\title{
LA TRADUCCIÓN DE LAS ESCRITORAS INGLESAS Y LA NOVELA ESPAÑOLA DEL PRIMER TERCIO DEL SIGLO XIX: LO HISTÓRICO, LO SENTIMENTAL Y LO GÓTICO
}

\author{
Helena Establier PÉREZ \\ Universidad de Alicante
}

\section{RESUMEN}

Aunque la escritura de las mujeres presentaba en la Inglaterra del primer tercio del siglo XIX un desarrollo y una madurez considerables, lo cierto es que la lista de novelistas británicas cuyas obras llegan en esa misma época a nuestro país es bastante reducida. Todos estos textos - que en conjunto no superan la veintena y que se traducen al español en las mismas fechas, la segunda y la tercera décadas del siglo- se enmarcan dentro de géneros populares, con gran presencia del didactismo y de lo sentimental, elementos derivados de las aventuras de la narrativa heroica e ingredientes del relato gótico que destacan sobre el fondo social costumbrista de la novela inglesa dieciochesca. Este trabajo se centra fundamentalmente en las escasas traducciones de obras de novelistas inglesas que presentan elementos y técnicas narrativas provenientes de los llamados gothic romances o gothic tales - que se han venido traduciendo al español como «novelas de horror o de terror»- género muy poco o nada frecuentado en la España de principios del XIX, en especial las de Sophia Lee, Regina Maria Roche y Ann Radcliffe. Su presencia en el panorama literario español del primer tercio del siglo XIX revela las demandas editoriales de un público de signo burgués y cada vez más femenino, deseoso de consumir las lecturas que entretenían a la clase media europea de su tiempo y de tener acceso a la escritura de las mujeres, tanto en el camino más trillado de lo didáctico-sentimental como en el más novedoso de la narrativa gótica.

Palabras clave: Traducción, novela, siglo XIX, escritoras, novela gótica, novela inglesa, novela sentimental, Sophia Lee, Regina Maria Roche, Ann Radcliffe.

\section{THE TRANSLATION OF ENGLISH WOMEN WRITERS AND THE SPANISH NOVEL IN THE FIRST THIRD OF THE 19TH CENTURY: THE HISTORICAL, SENTIMENTAL AND GOTHIC ELEMENTS}

\begin{abstract}
Though women writing was presenting in the England of the first third of century XIX a considerable development and a maturity, the certain thing is that the list of British novelists whose works arrive at that same time at our country is limited enough. All these texts - translated into Spanish in the same dates, the second and the third decades of the centuryare framed inside popular genres, with great presence of didactism and sentimentalism, elements derived from the adventures of the heroic narrative and ingredients of Gothic romances.
\end{abstract}


This paper focuses in the scarce translations from English women's novels presenting elements and narrative techniques characteristic of Gothic tales, a genre very inusual in Spain at the beginning os XIXth century, specifically the works of Sophia Lee, Regina Maria Roche and Ann Radcliffe. Its presence in the Spanish literary panorama of the first third of XIxth. Century reveals the publishing demands of a new public, more and more bourgeois and feminine, eager to consume the readings that entertained the European middle-class of his time and to have access to women writing, as much in the didactic and sentimental field like in the Gothic novel.

Key words: Translation, novel, xIxth. Century, Women writers, Gothic romances, English novel, sentimental novel, Sophia Lee, Regina Maria Roche, Ann Radcliffe.

1. TRADUCCIÓN Y NOVELISTAS INGLESAS EN LA ESPAÑA DEL PRIMER TERCIO DEL XIX: LO DIDÁCTICO Y LO SENTIMENTAL

Es ya bien sabido que las tres primeras décadas de nuestro siglo XIX no fueron especialmente fecundas en producción original de novelas. Las escasas - aunque imprescindibles - investigaciones con las que contamos al respecto apuntan, a la hora de justificar este escaso interés de los autores españoles por el género novelístico, a las particulares circunstancias históricas de la España del período: a las dificultades de la coyuntura bélica, por un lado, en los años comprendidos entre la invasión francesa y el regreso del rey Borbón, y posteriormente a la escasa flexibilidad ideológica de la España fernandina (1814-1833), que retraía a autores y traductores de servirse de las novelas como instrumentos políticos o como medios de expansión del pensamiento, al tiempo que los inducía a convertirlas en plataformas de difusión de valores socio-morales acordes con el modelo impuesto por la monarquía. Sabemos también, gracias a estos mismos estudios críticos, que, pese a la señalada escasez de novelas «autóctonas», la avidez de intrigas, aventuras, romances y lágrimas de los lectores españoles de principios del ochocientos fue de sobra colmada por el copioso número de traducciones que alegraban un tanto el escueto panorama narrativo de aquellos años ${ }^{1}$.

\footnotetext{
${ }^{1}$ Sobre las traducciones de novelas en el primer tercio del siglo XIX, resultan imprescindibles los siguientes estudios, que citaré a lo largo de este trabajo: FERRERAS, Juan I. Los orígenes de la novela decimonónica, 1800-1830. Madrid: Taurus, 1973; MONTESINOS, José F. Introducción a una historia de la novela en España en el siglo XIX. Seguida del esbozo de una bibliografía española de traducciones de novelas. 1800-1850. Madrid: Castalia, 1982. ALONSO SEOANE, M. ${ }^{\text {a }}$ José. «La narrativa de ficción en el Diario y la Gaceta de Madrid, 1808-1814». Salina, 2000, 14, pp. 107-114; «Traducciones de obras narrativas en el Diario de Madrid, 1814-1820». En: LAFARGA, F. (ed.). La traducción en España, 1750-1830. Lengua. Literatura, cultura. Lleida: Universitat, 1999, pp. 362373; «Traducciones de relatos de ficción en la Gaceta y el Diario de Madrid, 1823-1830». En: LAFARGA, F.; PALACIOS, C.; SAURA, A. (eds.). Neclásicos y románticos ante la traducción. Murcia: Universidad, 2002, pp. 19-33; Narrativa de ficción y público en Espa$\tilde{n} a$ : los anuncios en la «Gaceta» y en el «Diario de Madrid» (1808-1819). Madrid: Universitas, 2002.
} 
No es descabellado colegir que el aumento progresivo en el número de mujeres que sabían y deseaban leer, y que se decantaban por la afición novelesca, debió de ser un gran acicate para el control ejercido por la censura sobre las ideas y valores difundidos a través de las novelas, originales o traducidas, que se pretendía fueran muestrarios de buenas costumbres, salud moral y ejemplaridad femenina, máxime si quien las firmaba pertenecía también al «bello sexo»². En este sentido, los mensajes entre mujeres —incluso si cobraban forma novelesca - requerían el máximo escrúpulo, al invitar de una manera espontánea a una suerte de solidaridad de género que sólo podía ser permisible en tanto en cuanto sirviera para respaldar la ideología y el estatus vigentes, y no para cuestionarlos. El control de las novelistas autóctonas no debió de constituir una tarea especialmente ardua para la censura fernandina, a la vista del escasísimo número de escritoras españolas que encontramos entre el cambio de siglo y la muerte del monarca ${ }^{3}$.

${ }^{2}$ Como bien señala URZAINQUI para finales del siglo anterior, «aunque la escasez de fuentes no permita, hoy por hoy, determinar con exactitud cuánto y qué leían las mujeres en el siglo XVIII, sobran evidencias indirectas que muestran la intensificación de su relación con la lectura: lo que va a dar lugar a la configuración [...] de un sector nuevo y específico de público dentro del mercado editorial. Este sector creciente de población lectora que representan las mujeres hace que autores y editores se afanen por conocer sus preferencias y captarlas como compradoras publicando obras que les interesen. Muchas son educativas y de instrucción [...] ; pero muchas también , y sobre todo, de recreo y entretenimiento, novelas fundamentalmente, de las que son devoradoras natas. Si damos crédito a las repetidas protestas declaradas en prólogos, solicitudes de licencia y anuncios en la prensa, en sus ofertas editoriales las razones educativas priman sobre cualquier otras [...]. Inevitablemente, la demanda de este nuevo sector de público acaba por imponerse en el mercado editorial. Como se impone también — es la otra cara de la moneda - la literatura que trata de aleccionarlo y dirigirlo» (URZAINQUI, Inmaculada. «Nuevas propuestas a un público femenino». En: INFANTES, Víctor; LOPEZ, François; BOTREL, Jean-François (dirs). Historia de la edición y de la lectura en España. 1472-1914. Madrid: Fundación Germán Sánchez Ruipérez, 2003, pp. 481-491. La cita es de las pp. 486-487).

Según SIMÓN PALMER, la situación no presenta grandes variaciones a lo largo del XIX, advirtiéndose constantemente del peligro de la lectura de novelas para la estabilidad moral y mental de las mujeres, prohibiéndola y controlándola aún en los años 80 (SIMÓN PALMER, $\mathrm{M}^{\mathrm{a}}$ del Carmen. «La mujer lectora». En: INFANTES, LÓPEZ y BOTREL (dirs.). Op. cit., p. 750).

${ }^{3}$ No alcanzamos a citar más de media docena de escritoras entre todos aquellos que ejercen su actividad literaria entre el cambio de siglo y 1835 . Dejando aparte las obras de las autoras más conocidas como Vicenta Maturana o Segunda Martínez de Robles, de las otras firmadas con nombre de mujer siquiera podemos afirmar con seguridad que no se trate de traducciones de textos franceses, tal como algunas de ellas rezan en su portada, en un intento quizá de sus autoras de garantizarse una mejor acogida entre el público lector y/o de disfrazar su intromisión en el ámbito masculino de la creación literaria. Es el caso, por ejemplo, de La invención del órgano, o Abassa y Bermécides (Madrid, 1831) de María Belloumini, y de Reynaldo y Elina, o la sacerdotisa peruana (Valencia, 1820) de Antonia Tovar y Salcedo, que se reconocen en su portada como traducciones de novelas históricas (FERRERAS, Juan I. 
Parece bastante evidente que la realidad histórico-social de la España de Fernando VII invitaba a sus mujeres al silencio, a encajar en un ideal doméstico y familiar que no incluía la exhibición pública de la voz de las mujeres a través de la creación literaria. Sin embargo, la escritura femenina, bien que no acababa de dar sus frutos en nuestro país, sí llegaba a él desde más allá de sus fronteras, desde Francia e Inglaterra, a través de novelas morales y educativas - por supuesto- y también de otras que no lo eran tanto, pero que se esforzaban por presentarse como aviso de navegantes para jóvenes inquietas o excesivamente proclives a los engaños de los sentidos. La lista de autoras extranjeras que llegó a nuestro país en traducción en las tres primeras décadas del siglo XIX no es, como veremos, demasiado extensa, aunque en cualquier caso supera con creces la producción autóctona, fundamentalmente por la abundancia de reediciones de los textos de algunas de ellas —Le Prince de Beaumont es un buen ejemplo-, cuyo eco fue espectacular en nuestro país.

Entre las francesas, prevalecieron las traducciones de narrativa pedagógico-moral para niños y adultas —algunas de aquéllas venían ya editándose desde el último tercio del siglo XVIII-, como las de Madame de Genlis, Madame de Graffigny, Madame Le Prince de Beaumont, Madame de Renneville, Mme. Riccoboni o Joséphine de Lasteyrie du Saillant, aunque también hay lugar para las aventuras sentimentales con fondo moral de Madame de Cottin o Madame Tercy o las más disparatadas de Louise Brayer de Saint-Léon, e incluso para alguna obra gratificante e inesperada como Urika de la Duquesa de Duras ${ }^{4}$.

Por su parte, la lista de escritoras inglesas cuyas novelas llegan en esta misma época a nuestro país no es mucho más larga, lo cual contrasta vivamente con el desarrollo y la madurez literaria que la escritura de las mujeres presentaba ya en el primer tercio del XIX al otro lado del Canal de la Mancha. Sabemos de sobra, a través de los estudios más recientes sobre la narrativa inglesa del cambio de siglo, que el incremento de la producción novelística a finales del setecientos fue especialmente notable en el caso de las escritoras ${ }^{5}$, hasta el punto de que las contribuciones de

Catálogo de novelas y novelistas españoles del siglo XIX. Madrid: Cátedra, 1979; Los orígenes de la novela decimonónica, 1800-1830. Op. cit.; MONTESINOS, José F. Introducción a una historia de la novela en España en el siglo XIX. Op. cit.; BROWN, Reginald F. La novela española 1700-1850. Madrid: Dirección General de Archivos y Bibliotecas, 1953).

${ }^{4}$ MONTESINOS, José F. Introducción a una historia de la novela en España en el siglo XIX, op. cit, pp. 168, 177, 198-245; ALONSO SEOANE, M. ${ }^{a}$ José. «Traducciones de relatos de ficción en la Gaceta y el Diario de Madrid, 1823-1830». Art. cit, p. 24).

${ }^{5}$ WATT, Ian. The Rise of the Novel. Harmondsworth: Penguin, 1963; TODD, Janet. The Sign of Angelica: Women, Writing and Fiction, 1660-1800. New York: Columbia University Press, 1989; SPENCER, Jane. The Rise of Woman Novelists: from Aphra Behn to Jane Austen. Oxford: Blackwell, 1986; TURNER, Cheryl. Living by the pen: Women Writers in the Eighteenth Century. London: Routledge, 1997; TOMPKINS, Joyce M.S. 
éstas llegaron a igualar numéricamente las de sus colegas varones e incluso a superarlas en algunos subgéneros como la novela epistolar ${ }^{6}$. Los más relevantes periódicos y revistas británicos de la segunda mitad del XVIII incluyeron las reseñas críticas de sus obras, y pese a los evidentes condicionantes de su sexo, algunas de estas escritoras merecieron calurosos elogios de los críticos, como son los casos de Frances Burney, Charlotte Smith, Charlotte Lennox, Elizabeth Inchbald y Ann Radcliffe ${ }^{7}$.

La mayoría de los textos de estas escritoras no llegó a España ni en su tiempo ni en el primer tercio del XIX. De hecho, de los dos centenares de autoras inglesas que escriben entre 1770 y 1799, sólo son unas pocas aquellas cuyas novelas encuentran traducción al español antes de 1830: Regina Maria Roche, Agnes Bennet, Amelia Opie, Sophia Lee, Elizabeth Helme, Charlotte Lennox y Ann Radcliffe. De la mayoría de ellas, además, se vierten a nuestro idioma obras aisladas, en ocasiones ni siquiera las más vendidas en su país de origen, con la excepción de Elizabeth Helme y especialmente de Ann Radcliffe, cuyas novelas parecen tener una acogida especialmente notable. En definitiva, los textos de escritoras inglesas trasladados al español no son copiosos -no superan, en conjunto, la veintenapero presentan elementos comunes que revelan una cierta comunidad de gustos e intereses en sus traductores y en su público lector: señalemos, para empezar, que casi todos obedecen a un criterio cronológico común, decantándose por originales relativamente recientes, editados entre 1785 y $1803^{8}$;

The Popular Novel in England, 1770-1800. Lincoln: University of Nebraska Press, 1961; BLAIN, Virginia; CLEMENTS, Patricia; GRUNDY, Isobel. The Feminist Companion to Literature in English. New Haven (London): Yale University Press, 1990.

${ }^{6}$ Sin llegar a las afirmaciones de Ian Watt, que en su citado estudio The Rise of the Novel señalaba que la mayoría de las novelas dieciochescas inglesas fueron escritas por mujeres, James Raven y Antonia Forster afirman más recientemente que el número de escritores de novela en Inglaterra entre 1770 y 1799 alcanzaba la cifra de 292, mientras que las autoras llegaban a 189. Las cifras se equilibran un tanto en lo relativo al número de novelas publicadas, 419 de autoría masculina frente a las 407 de autoría femenina (RAVEN, James y FORSTER, Antonia. The English Novel 1770-1829: A Bibliographical Survey of Prose Fiction Published in the British Isle. Oxford: Oxford University Press, 2000, p. 48). Afinando un poco más, señalan los autores que de las 64 novelas que tuvieron más de cinco ediciones entre 1770 y 1829, 30 de ellas están escritas por mujeres, incluyéndose en este grupo cinco obras de Ann Radcliffe, las tres primeras de Frances Burney, dos de E. Inchbald, el Champion of Virtue de Clara Reeve, etc. (Ibid., p. 39). Ninguna duda nos cabe, a tenor de estos datos, de la popularidad de las novelistas inglesas entre finales del siglo XVIII y principios del XIX.

${ }^{7}$ Laura Range revisa las reseñas críticas de todas las novelas aparecidas en los diarios de la época y ofrece una lista completa de éstas en «Momentary fame: Female Novelists in Eighteenth-Century Book Reviews». En: BACKSCHEIDER, Paula; INGRASSIA, Catherine (eds.). A Companion to the Eighteenth-Century English Novel and Culture. Oxford: Blackwell, 2005, pp. 276- 298.

${ }^{8}$ Es una excepción Bernardo María de la Calzada, que elige para trasladar al español una obra «antigua» de Charlotte Lennox, The Female Quixote (1752). Esta traducción, que se 
coinciden también en las fechas de publicación, ya que -exceptuando alguna que obtiene una primera edición en los últimos años del XVIII o primeros del XIX ${ }^{9}$ - la mayoría ve la luz en español entre 1817 y 1835. Pero además, todos los textos traducidos se enmarcan dentro de uno o varios géneros populares, como una suerte de «pastiches» literarios con una mezcla de elementos herederos de las aventuras de la narrativa heroica (romance), una fuerte presencia del didactismo y de lo sentimental con ingredientes del relato gótico articulados en proporción variable, y el fondo social costumbrista habitual en la novela (novel) inglesa dieciochesca.

En este sentido, la distinción entre romance y novel, propia de la narrativa inglesa del setecientos, resulta fundamental para entender adecuadamente la obra de la mayoría de las escritoras de finales del siglo, pioneras en conseguir una mezcla de elementos realistas y románticos que afecta al propio desarrollo del género novelístico ${ }^{10}$. Todas ellas, incluso las que se inclinaban hacia una narrativa más realista — como Aphra Behn, Eliza Haywood o Delarivier Manley-, experimentaron la influencia de las novelas heroicas francesas del XVII, que llegaron a considerarse ya en el setecientos un género propiamente «femenino». Estas narraciones de disparatadas aventuras caballerescas por el amor de una dama complacían especialmente a las lectoras, ya que otorgaban a sus protagonistas un elevado poder amo-

publica con el curioso título de Don Quijote con faldas o Perjuicios morales de las disparatadas novelas, es de 1808. (Incluyo un listado de todas las traducciones de novelas inglesas citadas al final de este trabajo).

${ }^{9}$ The Children of the Abbey (1796) de Regina Roche, se había publicado extractada en 1808, como parte de la Biblioteca Británica de Olive, donde también aparecieron algunos de los Cuentos de Canterbury, de Harriet Lee. Posteriormente, entre 1818 y 1820 , vuelve a aparecer (completa, en seis volúmenes) y con nuevo título: Oscar y Amanda, o los descendientes de la abadía. De la hermana de Harriet Lee, Sophia, se publica en 1795 The Recess (1785) con el título de El subterráneo o la Matilde, obra que se edita de nuevo en 1817 con el título El subterráneo o las dos hermanas, Matilde y Leonor. Respecto a las obras de Helme, las dos primeras, Luisa o la cabaña en el valle y Alberto el desierto de Strathnavern se publican, respectivamente, en 1797 y 1807 . Todas ellas aparecen recogidas en el listado de traducciones que aparece al final del artículo.

${ }^{10}$ Así explica Clara Reeve en 1785 la diferencia entre Romance y Novel:

«El Romance es una fábula heroica, que trata de personas y cosas fabulosas. La Novela es un cuadro de la vida y las costumbres reales, y de la época en la que se escribe. El Romance, en un lenguaje elevado, describe lo que nunca ha pasado y no es probable que ocurra. La Novela nos hace una relación de cosas como las que ocurren cada día ante nuestros ojos, las que podrían pasar a nuestros amigos o a nosotros mismos; y su perfección consiste en representar cada escena de una forma tan natural, y hacerla parecer tan probable, que nos convenza de que es real (al menos mientras estamos leyendo), hasta el punto de que nos sintamos afectados por las alegrías o los disgustos de los personajes de la historia como si fueran nuestros». (The Progress of Romance. Colchester: W. Keymer, 1785, 2 vols. La cita es de la edición facsímil. New York: Facsimile Text Society, 1930, vol. II, p. 86. La traducción es mía). 
roso sobre el hombre ${ }^{11}$, y por ende una relevancia social de la que las mujeres carecían absolutamente en la vida real. Las escritoras, por su parte, valoraban en el género heroico una actitud hacia aquéllas que reconocía la importancia de sus preocupaciones y sus derechos, y legitimaba la posibilidad de que la historia de una mujer pudiera también convertirse en el centro de una novela. Esta tendencia aparece en buena parte de la ficción feminocéntrica dieciochesca — Richardson es un buen ejemplo-, pero es desarrollada especialmente por las escritoras, independientemente de la disparidad de técnicas e inquietudes que animaran su producción literaria, hasta el punto de que en el XVIII lectores y críticos habían llegado a referirse a las producciones de las escritoras - sea cual fuere su tendencia narrativa- como romances ${ }^{12}$.

A partir de 1750 se establece un marco de convenciones para los textos novelescos, y ya se hace posible definir una «novela de mujeres», con la influencia de la narrativa heroica, pero especialmente infestada del didactismo y el sentimentalismo comunes a gran parte de la narrativa de la época $^{13}$. Si, como hemos señalado, las convenciones heredadas de la novela heroica francesa permitían a las escritoras centrar el interés narrativo en historias de mujeres, el ingrediente sentimental resultaba fundamental para trasladar las preocupaciones de la esfera doméstica al ámbito público. De hecho, la nueva valoración de lo privado y de lo doméstico que emerge del relato sentimental estandarizado a finales del XVIII contribuyó a generar cierta ambigüedad en la distinción entre lo público y lo privado —en consonancia, hasta el momento, con una tajante separación de sexos- y contribuyó a que las escritoras reclamaran a través de sus textos un espacio público, a que expresaran sus preocupaciones sobre el lugar de las mujeres en las estructuras sociales, y a que sugirieran que la comprensión de la historia podía ser modificada por la inclusión de una perspectiva que considerara también relevantes sus propias vidas ${ }^{14}$.

Así, hacia final del siglo, la forma dominante cultivada por las escritoras es la novela extensa, en varios volúmenes, con heroínas virtuosas que

${ }^{11}$ «A fantasy of female power, through which women could escape in imagination from the reality of their oppression» (SPENCER, Jane, op. cit., p. 187).

${ }^{12}$ A este respecto señala Ros Ballaster: «The popular association of the late seventeenth century romance with a female readership and female literary production, established a continuity between the female-authored 'novel' in England and the earlier romance despite their significant differences» (BALLASTER, Ros. Seductive Forms: Women's Amatory Fiction from 1684 to 1740. Oxford: Clarendon Press, 1982, p. 13).

${ }^{13}$ Para una valoración de la relevancia de lo sentimental en el origen de la novela inglesa, ver el reciente e interesante trabajo de AHERN, Stephen. Affected Sensibilities: Romantic Excesses and the Genealogy of the Novel, 1680-1810. New York: AMS Press, 2007.

${ }^{14}$ SPENCER, Jane. «Women writers and the eighteenth-century novel». En: RICHETTI, John. (ed.). The Cambridge Companion to Eighteenth-Century Literature. Cambridge: Cambridge University Press, 1996, pp. 212-235. 
se ven forzadas a abandonar la seguridad del espacio doméstico (fundamentalmente femenino) para reclamar su auténtica identidad o limpiar su honor, y que se enfrentan a numerosos obstáculos y a diferentes formas de violencia inherentes al ámbito público (por esencia masculino), todo ello con una presencia muy elevada del ingrediente sentimental y con un final feliz, que implica el restablecimiento de la armonía socio-familiar perdida y el casamiento por amor de los protagonistas.

Este es el patrón que marca buena parte de las obras de las escritoras inglesas traducidas a nuestro idioma en el primer tercio de siglo, y que nos sirve de referencia para establecer los gustos y expectativas de los lectores -y sobre todo de las lectoras- españoles de novelas. Así son, por ejemplo, las educativas -y soporíferas - obras de Elizabeth Helme ${ }^{15}$, que se editaron en español entre 1797 y 1842: Luisa o la cabaña en el valle fue la más popular (1797), y obtuvo varias ediciones y reediciones a lo largo de la primera mitad del XIX; le siguieron Alberto o el desierto de Strathnavern (1807), Saint-Clair de las Islas o los desterrados de la isla (1828) y El peregrino o Cristabela de Mowbray (1832) ${ }^{16}$. También pertenecen a esta tendencia didáctico-sentimental dos extensísimos best sellers de Agnes Bennet ${ }^{17}$ publicados originalmente por Minerva Press ${ }^{18}$ y traduci-

15 Poco se sabe de Elizabeth Helme ( $i ?-$ ¿1810?), calificada por Montague Summers como «ardiente educadora y muy prolífica con su pluma» (SUMMERS, Montague. A Gothic Bibliography. London: Fortune Press, 1940. P. 63. La traducción es mía). Escribió diez novelas, de las cuales sólo llegaron a España las cuatro señaladas en el texto. Louisa; or, the Cottage on the Moor (1787), la primera vertida a nuestro idioma, tuvo nada menos que cinco ediciones el primer año de su publicación en inglés, y siguió reimprimiéndose hasta bien entrado el XIX. La mayoría de sus novelas se centran en la moralidad personal, y en sus relaciones con el estatus económico y la clase social. Ella misma, en el Prefacio a una de sus obras, señala que sus propósitos como escritora eran los de «inculcar moralidad y amor al estudio» (Instructive Rambles Extended in London and Adjacent Villages. London: Sampson Low, 1800. P. 6. La traducción es mía).

${ }^{16}$ Ver listado final de obras traducidas citadas.

${ }^{17}$ La primera obra de Agnes Bennett (1750-1808), Anna; or Memoirs of a Welch Heiress (1785) tuvo un éxito clamoroso en Inglaterra y la tirada se agotó el primer día de su publicación. Fue, sin embargo, su obra The Beggar Girl and her Benefactors (1797) la que se convirtió en un auténtico best seller de la casa editorial Minerva Press. Estas dos obras fueron traducidas al español entre 1818 y 1820, y recogidas conjuntamente más tarde en 14 volúmenes con el título Colección de obras completas de Mistress Bennett (Ver listado final de obras traducidas). Además de estas, Bennett publicó otras que nunca encontraron traducción a nuestro idioma: Juvenile indiscretions (1786), Agnes De-Courci (1789), Ellen; or the Countess of Castle Howel (1794), y Vicissitudes Abroad; or the Ghost of my Father (1806).

${ }^{18}$ Minerva Press fue una conocidísma casa editorial establecida en Londres por William Lane, especializada en la publicación de novelas entre 1790 y 1820 . La mayoría de los títulos publicados por Minerva son obras de mujeres novelistas, muchos anónimos y otros con seudónimo. Con el tiempo, el nombre de esta casa editorial acabaría convirtiéndose en sinónimo de narrativa de segunda fila para mujeres. (Ver BLAKEY, Dorothy. The Minerva 
dos al español por Félix Enciso Castrillón entre 1818 y 1820: Ana o la heredera del país de Gales y Rosa o la niña mendiga y sus bienhechores), así como la única obra de Amelia Opie ${ }^{19}$ que llega a nuestro idioma: El padre y la hija (1820), obra de la traductora Juana Barrera.

Es evidente que la insistente presencia de lo sentimental que apreciamos en estas obras —en algunas, como la de Bennett, las lágrimas de unos y otras se hacen presentes en casi cada página de los 14 volúmenes que compone su obra completa en español—, así como la voluntad didáctica y moralizadora de la que hacen gala, son elementos comunes a la narrativa del ámbito cultural europeo desde las últimas décadas del XVIII, y muy especialmente de la que escriben las mujeres, y por tanto, están en perfecta consonancia con los cánones de la novela original española de la époc ${ }^{20}$. Pero junto a estos ingredientes hemos también de destacar en las novelas citadas - y fundamentalmente en otras a las que haremos referencia más tarde-, la presencia de elementos y técnicas narrativas provenientes de los llamados en su idioma original gothic romances o gothic tales, y que se han venido traduciendo al español como «novelas de horror o de terror», género - por cierto- muy poco o nada frecuentado en la España de principios del XIX.

\section{EL GÓTICO «FEMENINO» INGLÉS}

La novela gótica, de horror o terror ${ }^{21}$, sin duda el mayor éxito editorial de la literatura inglesa de las postrimerías del XVIII, constituye una nueva

Press 1790-1820. Oxford University Press: 1939; LASA ÁLVAREZ, Begoña. «Los grandes éxitos de la editorial inglesa Minerva Press». En Literatura y cultura popular en el nuevo milenio: actas del II Congreso Internacional de la Sociedad Española de Estudios de Cultura Popular. A Coruña: Universidade da Coruña, 2006, CD-Rom.)

${ }^{19}$ Además de The Father and the Daughter (1801), Amelia Opie (1769-1853) publicó otras novelas, como Adeline Mowbray; or The Mother and the Daughter (1804), basada en la vida de Mary Woolstonecraft - a quien conoció cuando frecuentaba los círculos intelectuales radicales en Londres-, Valentine's Eve (1816) o Madeline (1822), ninguna de las cuales se tradujo al español en el primer tercio del XIX. Desde 1825, fecha en que se hizó cuáquera, Opie sólo publico poesía.

${ }^{20}$ Ver los capítulos VII y VIII de Ferreras (FERRERAS, Juan I. Los orígenes de la novela decimonónica, 1800-1830, op. cit., pp. 169-242).

${ }^{21}$ La bibliografía en inglés sobre la novela gótica es realmente abrumadora. Recojo aquí solamente algunas de las revisiones recientes posteriores a los años ochenta: PUNTER, David. The Literature of Terror: a History of Gothic Fictions from 1765 to the Present Day. London: Longman, 1980; PUNTER, David; BYRON, Glennis. The Gothic. Malden. Oxford: Blackwell, 2004; HAGGERTY, George E. Gothic Fiction/Gothic Form. University Park: Pennsylvania State U.P., 1989; GRAHAM, Kenneth W. (ed.). Gothic Fictions: Prohibition/Transgression. AMS Press, 1989; BOTTING, Fred. Gothic. London: Routledge, 1996; KILGOUR, Maggie. The Rise of the Gothic Novel. London: Routledge, 1997; HORNER, Avril. European Gothic: A Spirited Exchange. 1760-1960. Manchester \& New York: Manchester University Press, 2002. 
forma de ficción romántica, diferente del cuento convencional de magia y caballerías, o de la narración realista de Richardson o Fielding. Su vertiginoso desarrollo desde 1764 (fecha en la que Horace Walpole publica The Castle of Otranto, considerada la primera muestra del género) hasta su momento culminante en el cambio de siglo constituye una de las principales manifestaciones de la rebelión artística que se produce en las últimas decadas del XVIII contra los principios estéticos de orden y unidad difundidos por el ideal neoclásico, para recobrar una reprimida libertad imaginativa, primitiva e incluso bárbara, que marca las pautas hacia la posterior eclosión romántica. Frente a la tiranía de la razón, lo gótico —enraizado en el folclore británico, en las aventuras romancescas, en la tragedia isabelina y jacobina, en la melancolía renacentista, en el concepto burkiano de lo sublime, en Ossian, Spencer, Milton, en las tradiciones germánicas (Schiller) y en las propias novelas sentimentales dieciochescas- estimulaba la imaginación y la sensibilidad de los lectores, enfrentándolos con lo sobrenatural, el misterio y el terror, como recordatorios, por un lado, de la inconsistencia de lo humano ante lo divino o lo metafísico, y como propuesta de liberación, por otro, de las emociones del corazón, reprimidas por el rigor del «augustanismo» ${ }^{22}$ propio de la primera mitad del siglo.

La novela gótica nació como un género híbrido, a medio camino entre la narración histórico-medieval propia del «romance» y la novela de costumbres, pero enmarcado en lo sobrenatural y en lo sentimental. A través de argumentos bastante convencionales, en los que los personajes negativos, representantes del materialismo moderno, amenazan la unidad social, las novelas góticas ofrecen una visión casi pesadillesca de su tiempo, fundamentada en las relaciones humanas predatorias y en un orden social insano, es decir, un mundo de individuos alienados y obsesos, en el que las mujeres suelen ser víctimas de la maldad general y de su propia pasividad femenina. Formalmente, el género bien pronto se convirtió en un muestrario de convenciones ${ }^{23}$, de situaciones y recursos que se reciclaban de un

${ }^{22}$ Con el término Augustanism se hace referencia, en el marco de la historia literaria inglesa, a las formas culturales propias de la Restauración (1660) y de la primera mitad del siglo XVIII, que encuentran su inspiración en el clasicismo antiguo como respuesta a las novedades propias de la literatura isabelina. Dryden, Pope, Thomson y Johnson son buenos ejemplos de la exigencia de orden y decoro, y del rigor formal que caracteriza la literatura del período, especialmente la poesía.

${ }^{23}$ La fórmula la ofrecía burlonamente un crítico anónimo en un ensayo de 1797 titulado «Terrorist novel writing» (Spirit of the Public Journals, I, p. 229):

Take- An old castle, half of it ruinous.

A long gallery, with a great many doors, some secret ones.

Three murdered bodies, quite fresh.

As many skeletons, in chests and presses...

Mix them together, in the form os three volumes, to be taken ay any of the watering-places before going to bed. 
texto a otro con la misma finalidad: escenarios terroríficos (castillos y abadías en ruinas, bosques oscuros y amenazadores, altísimas y escarpadas montañas), personajes estereotipados (heroínas perseguidas, héroes tan sensibles como poco eficaces, villanos terribles, abades demoníacos, criados excesivamente habladores), e instituciones encargadas de representar diferentes formas de opresión sobre los individuos (religión católica, Inquisición, familia, nobleza corrupta).

La crítica inglesa de su época las recibió con cierta ambivalencia, preocupada por el efecto moral que sus argumentos perversos y sus personajes extremos podían causar en el público lector. Dentro del marco general de prevención de moralistas y educadores contra la ficción novelesca, los relatos góticos fueron cuidadosamente analizados por los críticos, entendiendo que al estimular la imaginación y la sensibilidad de los jóvenes lectores, las novelas se convertían en fuerza subversiva que los alejaba de la realidad y alimentaba en ellos pensamientos extravagantes así como toda suerte de deseos destructivos y antisociales.

No olvidemos, a este respecto, que una buena parte de las novelas góticas inglesas del setecientos está escrita por mujeres, y tampoco que el público lector de aquéllas era mayoritaramente femenino, hechos que explican a la perfección el desvelo de los críticos dieciochescos por exponer las consecuencias negativas de consumirlas y sus repercusiones en el orden social. Las primeras sucesoras de Walpole en las décadas de los setenta y los ochenta, además de Thomas Leland, fueron mujeres: Clara Reeve —que preparó magníficamente el camino para el posterior éxito de Ann Radcliffe- Sophia Lee, y también otras menos conocidas, como Agnes Musgrave o Anne Fuller, que integran la llamada escuela «histórico-gótica» ${ }^{24}$. Sólo unos años más tarde, entre 1790 y 1798, el género llega a su máximo esplendor con las principales novelas de Ann Radcliffe y de Regina Roche, buena parte de las cuales se traduce posteriormente a nuestro idioma. Este insistente cultivo de la novela de horror por parte de las escritoras, que la crítica anglosajona más reciente recoge bajo el epígrafe de «gótico femenino» (female gothic), proporciona al género unos rasgos propios y diferenciados dentro del marco general de la narrativa gótica finisecular ${ }^{25}$.

${ }^{24}$ Tomo prestada la etiqueta «histórico-gótico» de Devendra P. Varma, que enmarca el desarrollo de esta escuela entre las obras de Horace Walpole (The Castle of Otranto) y las de Walter Scott (VARMA, Devendra P. The Gothic Flame: Being a History of the Gothic Novel in England, its Origins, Efforescence and Residuary Influences. London: Barker, 1957).

${ }^{25}$ En su interesantísima introducción a The Female Gothic, Juliann E. Fleenor resume las características de los textos góticos femeninos a lo largo de la historia en los siguientes términos:

1. No presentan una forma textual común y específica, salvo la de la búsqueda o indagación.

2. Se sirven de escenarios tradicionales, el castillo en ruinas o la habitación cerrada, para simbolizar la situación de la heroína y de la cultura. 
Recordemos que las novelas góticas de autoría masculina, fundamentalmente a partir de los años noventa, se decantan por la estética del horror, a través de historias de lujuria y magia negra, con héroes rebeldes que persiguen el elixir de la vida, esconden pecados imperdonables, realizan pactos satánicos, crean monstruos en laboratorios, e incluso salen de la tumba para succionar la sangre de víctimas inocentes. Todos sus personajes presentan serias dificultades para integrarse en la sociedad y definir una identidad individual, que tratan de perfilar en no pocas ocasiones a través de la rivalidad y del conflicto edípico con sus precursores. El desenlace del conflicto suele ser revolucionario, desafiando las presiones sociales que reprimen el deseo individual. Aunque Vathek (1786), de Beckford, es la primera en términos cronológicos, The Monk (1796) de Matthew Lewis es la más popular de las ficciones góticas masculinas anteriores al cambio de siglo, posiblemente por la heterodoxia de su protagonista principal, el padre Ambrosio, víctima de una alienación religiosa, social y familiar que lo convierte en verdugo sometido a todo tipo de pasiones ilí$\operatorname{citas}^{26}$. En esa misma corriente, caracterizada por la violencia y la crudeza de sus escenas, se encuentran las obras de Godwin (Caleb Williams, 1794), y algo más tarde - ya en la clara estela de Romantiscimo- las de Polidori (Vampyre, 1819), Maturin (Melmoth the Wanderer, 1820) e incluso el Frankenstein (1818) de Mary Shelley.

$\mathrm{Ni}$ que decir tiene que ninguna de estas obras se tradujo dentro de nuestras fronteras en el primer tercio del siglo XIX, ya que sus contenidos, que escandalizaron a la propia crítica anglosajona, no se adecuaban en absoluto a las pretensiones moralizadoras y educativas que lastraban nuestra práctica novelística ni encajaban, las más de las veces, con el reaccionarismo ideológico fernandino. Sabemos sobradamente que la presencia del horror o de lo gótico en nuestro país es limitada o casi inexistente en las primeras décadas del $\mathrm{XIX}^{27}$, probablemente por los motivos señalados más

3. Provocan sentimientos de terror y de rabia, incluso de auto-repugnancia, dirigidos hacia el papel de las mujeres, la sexualidad o la fisiología femeninas, y la procreación.

4. Usan formas narrativas que cuestionan la validez de la narración en sí misma.

5. Reflexionan sobre el paradigma patriarcal que se construye sobre la orfandad de madre de todas las mujeres, y que determina que, por no ser hombres, éstas constituyen formas incompletas (FLEENOR, Juliann E. The Female Gothic. Montréal / London: Eden Press Inc., 1983. P. 15)

${ }^{26}$ Capaz de todos los excesos imaginables, tras violar a su propia hermana y asesinar a su madre, Ambrosio, en la genuina estela del mito faústico, entrega su alma a Satán y acaba en el fondo de un precipicio, devorado por la implacable madre naturaleza. La obra fue traducida al español en Madrid en 1821, con el título El fraile, o historia del padre Ambrosio y de la bella Antonia.

${ }^{27}$ Los estudios sobre la presencia de lo gótico en la literatura española de este período son escasos, y coinciden en señalar la limitada presencia del horror en el teatro autóctono y, sobre todo, en la novela. A este respecto, conviene consultar: GUILLERMO, Carnero. La 
arriba, pero también por la discordancia entre el contexto socio-político europeo, que propicia el auge de la novela gótica a fines del XVIII, y el que se disfrutaba en la España del ochocientos, al menos hasta el final del absolutismo ${ }^{28}$.

Sea por los motivos que fuere, lo cierto es que más allá de la Galería Fúnebre de Espectros y Sombras Ensangrentadas (1831) de Agustín Pérez Zaragoza y alguna otra narración aislada ${ }^{29}$, y del uso de las convenciones

cara oscura del Siglo de las Luces. Madrid: Cátedra, 1983, pp. 95-123; «Sensibilidad, terror y medievalismo en la narrativa del siglo XVIII». En La cara oscura del Siglo de las Luces. Madrid: Fundación Juan March, 1983, pp. 95-123; «La Holandesa de Gaspar Zavala y Zamora y la literatura gótica del XVIII español». En: ROMERA, J.; FREIRE, A; LORENTE, A. (coords.). Homenaje al profesor José Fradejas Lebrero, II. Madrid: UNED, 1993, pp. 517-539; CUENCA, Luis A. de «La literatura fantástica española del siglo XVIII». Cuadernos Hispanoamericanos, 1984, 410, pp. 107-118; «Prólogo» a Agustín Pérez Zaragoza. Galería Fúnebre de Espectros y Sombras Ensangrentadas. Madrid: Editora Nacional, 1977; FERRERAS, Juan I. Los orígenes de la novela decimonónica. Op. cit., pp. 243-264; CALDERA, Ermanno. «Il teatro del pathos e dell'orrore al principio dell'ottocento: fedeltà ai canoni del classicismo e presentimenti romantici». Entresiglos, 1991, I, pp. 57-75; GLENDINNING, Nigel. «Lo gótico, lo funeral y lo macabro en la cultura española y europea del siglo XVIII». Anales de Literatura Española, 1994, 10, pp. 101-115; HAIDT, Rebecca. «How gothic is it?. The Galería Fúnebre, panoramic seeing and enlightenment visuality». Dieciocho, 2003, vol. 26, núm. 1, pp. 115-129; GIES, David. T. «Larra, La Galería Fúnebre y el gusto por lo gótico». En Atti IV Congreso sul Romanticismo Spagnolo e Ispanoamericano. Genova: Universidad, 1988, pp. 60-68; HERRERO, Javier. «Terror y literatura: ilustración, revolución y los orígenes del movimiento romántico». En La literatura española de la Ilustración. Homenaje a Carlos III. Madrid: Universidad Complutense, 1989, pp. 131-153.

${ }^{28}$ A este respecto, señala Varma que la novela gótica «is a subtle and complex aesthetic expression of the spirit of Europe in revolutionary ferment. It is the most characteristic literary expression of the orgy of mental and emotional excitement that accompanied the French Revolution and grew out of the Industrialization of Britain». (Op. cit., p. 217). Varma establece así una relación directa entre el Terror francés y las novelas inglesas de terror, argumentando que la inseguridad y la excitación generados por la Revolución hubieron de afectar en general a la creación literaria, y en especial, a los escritores de novela gótica. Los escritores ingleses eran conscientes de la imparable decadencia del antiguo orden de cosas, de los cambios que se estaban produciendo en las estructuras sociales, y su frustración individual ante esta transformación del mundo toma forma literaria en las constantes escenas de horror y de violencia con que nos deleitan las novelas góticas. (Ibid., pp. 217-218). Nada similar podía estimular en la España fernandina el cultivo del género de horror, de forma que los pocos ejemplos que de él tenemos a principios del XIX, denotan —más que la respuesta literaria a una realidad social - el deseo de sacar partido a unas convenciones literarias de notable éxito en el extranjero e incluso una sensibilidad temprana a algunos rasgos de los que van a caracterizar la nueva estética romántica.

${ }^{29}$ El único nombre que recoge Ferreras es el de Narciso Torre López y Ruedas, cuya obra Virtud, constancia, amor y desinterés, aparecen en el bello sexo (1834) parece esconder abundantes ingredientes góticos (crímenes, villanos, encerramientos en subterráneos, cadáveres degollados, heroínas encadenadas y amenazadas, etc.) También apunta Ferreras hacia algunas obras anónimas, como La urna sangrienta (Valencia, 1834), como posibles novelas góticas (Los orígenes, op. cit., pp. 261-263). 
del género que podamos encontrar en el teatro de la época, los ejemplos con los que contamos se limitan a las obras extranjeras de finales del XVIII traducidas en aquel periodo. Debemos señalar que los pocos ejemplos de narrativa gótica o pseudogótica que llegaron a nuestro país en esa época estaban firmados por mujeres inglesas, posiblemente porque en sus plumas las convenciones propias del género se ponían en juego con unos objetivos distintos a los de sus colegas hombres, una finalidad que - a diferencia de las obras de Lewis o de Maturin - no pasaba por la transgresión total y absoluta de los códigos sociosexuales ni por la manifestación literaria del horror llevado a sus últimas consecuencias.

En este sentido, todos los textos góticos femeninos se muestran animados por una misma idea, que vertebra la acción principal de la novela y determina el resto de subacciones o tramas subisidiarias que conforman su complejo entramado narrativo: el cuestionamiento de un modelo social y doméstico - a partir de la asunción del hogar como célula básica de la sociedad- deshumanizado, agresivo e injusto, en el que las mujeres son siempre víctimas. El trasfondo ideológico - la representación de la opresión y la represión experimentadas por el individuo en un mundo hostiles pues similar al de las novelas escritas por los hombres, aunque en este caso sus víctimas sean siempre mujeres - y también los héroes «feminizados» que las arropan-, y pese a que su final suponga —a diferencia de los desenalaces de las obras de autoría masculina - una recomposición del orden y la armonía perdidos, es decir, una restauración del equilibrio textual y socio-familiar sin mediar rupturas peligrosamente transgresoras.

Las heroínas de las novelas góticas femeninas, las de Roche, Lee o Radcliffe, se ven amenazadas por un entorno familiar hostil, que las lleva en ocasiones a abandonar el núcleo doméstico o ser injustamente expulsadas de él para recorrer unos escenarios aterradores, de pasadizos subterráneos, castillos en ruinas, conventos o bosques horripilantes, donde se enfrentan a un sinfín de misterios y visiones sobrenaturales que al final siempre encuentran explicación racional. Su periplo por el amenazador mundo exterior se resuelve también positivamente, y al final de las novelas triunfa el amor, lo cual implica la formación de una nueva familia burguesa, equilibrada y confortable, así como la vuelta de la heroína a la seguridad del espacio doméstico ${ }^{30}$.

${ }^{30}$ Diane Long Hoeveler señala que, al final de las novelas góticas escritas por mujeres, las instituciones opresoras (prisión, convento, familia, asilo, etc.) son incorporadas y reconstruidas por la heroína como espacios «feminizados», la protagonista reinventa la familia de clase media, formada por cónyuges «compañeros», y hace nacer una nueva clase social, la burguesa, purificada ya de los excesos que caracterizaron a la aristocracia y que le impidieron presidir la nueva sociedad industrializada. En este proceso, la heroína renuncia también a sus tendencias hacia el exceso emocional, y cultiva una mente «racional» $\mathrm{y}$ «mascu- 
Lo gótico femenino representa así — para la heroína y la lectora- una subversión temporal del orden, que finaliza con la restauración de una norma - el matrimonio y la vida familiar- que, tras la experiencia de «terror» vivida en el exterior, se antoja tremendamente deseable. En todas ellas acaba castigándose cualquier rebelión contra la moral —en algunas incluso con la propia vida - y se reafirma un sistema de orden familiar y social, que requiere para su consecución la exposición de la mujer al espacio público, pero que se cierra al final con la desaparición de las formas «góticas» de domesticidad y con el retorno al hogar ${ }^{31}$. En definitiva, aunque algunos moralistas conservadores desconfiaran del potencial imaginativo de la novela gótica escrita por mujeres, lo cierto es que su mensaje final - la esfera doméstica como único final apropiado para las aventuras femeninas- no podía ser más correcto en términos morales, lo cual explica en gran medida su presencia y su aceptación en la España de principios del XIX.

\section{LaS escritoras de nOVEla GÓtica en España: Sophia Lee, Regina MARIA ROCHE Y ANN RADCLIFFE}

Tres son las autoras de novela gotica o seudogótica cuyas obras son traducidas al español en las primeras décadas del siglo XIX. La más antigua es la de Sophia Lee ${ }^{32}$, El subterráneo (The Recess or a Tale of Other Times, 1785) publicada muy pronto - 1795 - en tres volúmenes, y de nuevo en 1817, ya en la época de esplendor de la novela inglesa femenina en España. Se trata, en realidad, de un relato seudohistórico, cuyas protagonistas son las dos supuestas hijas gemelas de la reina María Estuardo - soberana de los escoceses-, nacidas de su matrimonio secreto con el Duque de Norfolk, y escondidas de la corte de Elizabeth Tudor por su propia madre para evitarles su amarga suerte. La novela está narrada en forma epistolar por Matilda, una de las dos hermanas, pero esto no impide que constituya un auténtico entramado de voces femeninas, ya que al tiempo que la protagonista cuenta su propia historia, permite también que se filtren las de su hermana Leonor y otras protagonistas, intercaladas en su

lina» que le permite controlar sus emociones (LONG HOEVELER, Diane. Gothic Feminism. The Professionalization of Gender from Charlotte Smith to the Brontës. Liverpool: University Press, 1998, pp. 22-23; 31).

${ }^{31}$ Ver KILGOUR, op. cit, pp. 3-43.

${ }^{32}$ Sophia Lee (1750-1824) fue dramaturga y novelista. Además de The Recess (1785), publicó otras dos novelas, que no encontraron traducción al español: Life of a Lover (1803), texto semi-autobiográfico y epistolar, y Ormond; or The Debauchee (1810). También es autora de la historia inicial y de dos de los doce cuentos de la colección de su hermana Harriet, Canterbury Tales (1797-1805). La escritora es conocida también por haber establecido una escuela para señoritas en Bath, junto con su hermana Harriet, a la que asistió, entre otras, la misma Ann Radcliffe. 
propia narración en forma de cartas y cuentos. A través de esta multiplicidad de voces y de personajes femeninos, Lee plantea un retrato muy complejo del poder y del potencial de las mujeres, de su lugar en la historia, de las relaciones femeninas, de la educación de las mujeres y sobre todo, de sus conflictos con el sistema patriarcal. En este sentido, el título de la obra, El subterráneo, adquiere un significado plenamente simbólico, representando no sólo el encierro concreto de Matilda y Leonor en los pasadizos de una vieja abadía en ruinas, sino el de todo su género, privado del conocimiento, la experiencia y el deseo sexual. La obra de Lee es, en realidad, una reivindicación feminista con forma de novela gótica, que, a través de la ficción histórica, denuncia la debilidad de la posición las mujeres en la sociedad de su tiempo. Los recursos del género de horror, incipiente aún en el año en que se escribe la novela (1785), están presentes en su forma convencional de escenarios (túneles oscuros en abadías en ruinas) o motivos (denuncia de instituciones opresoras como la Iglesia católica), e incluso se recurre tímidamente al uso de lo sobrenatural mediante sueños proféticos o voces y visiones inesperados, pero no llegan a alcanzar el nivel simbólico de otros relatos góticos ni se convierten en ningún momento en el núcleo de la novela, cuyo objetivo principal circula por otros derroteros más cercanos a las preocupaciones vitales de su autora, que hubo de enfrentarse en solitario desde bien joven a la sociedad de su tiempo ${ }^{33}$.

Las otras dos novelistas cuyas obras se insertan dentro de la corriente «gótica»y son traducidas al español pertenecen a la generación del cambio de siglo: Regina Maria Roche y Ann Radcliffe. La primera de ellas ${ }^{34}$ fue autora - entre otras obras - de un afamado best seller, The Children of the Abbey (1796), de gran eco en su tiempo e incluso bastante más adelante — para 1825 ya había alcanzado diez ediciones, y se siguió publicando hasta 1882 - , que en 1808 se editó en español extractado, como parte de la Biblioteca Británica de Olive (Los niños de la abadía). La obra volvió a aparecer un año después de El subterráneo de Lee, completa (nada menos que en seis volúmenes) y con nuevo título: Oscar y Amanda, o los

${ }^{33} \mathrm{Su}$ madre, que era actriz, falleció cuando sus hijos eran pequeños, y Sophia Lee ocupó su lugar en el cuidado familiar al mismo tiempo que escribía la comedia The Chapter of Accidents, representada con gran éxito en 1780 y publicada ese mismo año. Después de la muerte de su padre, en 1781, usó las ganancias obtenidas con este estreno para establecer en Bath la escuela de señoritas (ver nota anterior), que se convirtió también en hogar para sus hermanas huérfanas. No obstante, no abandonó su carrera como dramaturga, estrenando en 1796 la tragedia Almeyda, Queen of Grenada en Drury Lane.

${ }^{34}$ Regina Maria Roche (¿1764?-1845) escribió nada menos que dieciséis novelas, siendo la mayoría de ellas publicadas por William Lane en Minerva Press, y reeditadas hasta los años treinta. De hecho, Roche fue una de las grandes incondicionales de esta casa editorial inglesa; el éxito sin precedentes de The Children of the Abbey no fue más que un reflejo del alcanzado por Minerva Press, que encuentra su cumbre en los años noventa. 
descendientes de la abadía (1818-1820), en una traducción de José Melcior que se editó posteriormente en no pocas ocasiones.

La obra cuenta las aventuras y desventuras de dos hermanos dotados de todas las virtudes, Amanda y Óscar, descendientes de una poderosa familia escocesa propietaria de la Abadía de Dunreath. Injustamente privados de sus derechos sucesorios por mezquinas intrigas familiares, también son acosados por un villano, el Coronel Belgrave, que no duda en alcanzar las cotas máximas de ruindad para vengarse de la negativa del padre de Amanda a bendecir sus viles intenciones hacia la joven. A lo largo de los seis volúmenes que la obra comprende en español, los nietos del Conde Dunreath, Óscar y Amanda, se quedan huérfanos y pasan por tribulaciones de todo tipo - dificultades económicas, humillaciones sociales, acoso sexual, etc.-, que obstaculizan la consecución de su felicidad y su bienestar. Finalmente, triunfan la virtud y el amor, los dos hermanos recuperan título, herencia y dignidad, y consiguen unirse en matrimonio a otros jóvenes de similares cualidades e idéntico rango social.

Aun incluido habitualmente entre los relatos góticos, Óscar y Amanda queda bastante lejos de serlo. Presenta, eso sí, una atractiva combinación de realismo doméstico, ambientación contemporánea con toques góticos, argumento convencional incluyendo herencia perdida y recuperada, y una gran dosis de sentimentalismo, lo cual - a decir verdad- es también habitual en las narraciones de horror ${ }^{35}$. El ingrediente gótico aparece levemente en las escasas páginas dedicadas, en el primer y en el quinto volumen, a la segunda esposa del Conde Dunreath, quien, tras expulsar a su hijastra Malvina del castillo en medio de una tormentosa noche, experimenta sueños y visiones terroríficos, que no son otra cosa sus propios remordimientos. Muchos años después, Amanda, hija de la repudiada Malvina, vuelve a la abadía de sus antepasados, que, abandonada y en ruinas, se ha convertido en foco de leyendas locales sobre espectros y apariciones. Tras una serie de episodios misteriosos que parecen tener explicación sobrenatural, la joven descubre que el origen de los mismos no es otro que

${ }^{35}$ Coincido absolutamente con Elizabeth MACANDREW (The Gothic Tradition in Fiction. New York: Columbia University Press, 1979, p. 24) cuando relaciona de forma directa el relato sentimental y la novela gótica. De hecho, la estudiosa señala que la segunda no es sino una expresión de la otra cara de las ideas benevolentes expresadas por la novela sentimental, y añade lo siguiente: «It forms a variant of the Sentimental genre, with related structures, forms, and devices. Sentimental novels reflect an ideal that, coming from God is possibly realizable; the Gothic represents the distortion of that ideas». De hecho, aunque en las dos es habitual encontrar personajes femeninos estereotipados en la dicotomía bien/mal, en la sentimental ambos —el bien y el mal— son fácilmente identificables y asociables a personajes concretos, mientras que en las narraciones góticas - especialmente en las que escriben las mujeres - las heroínas sufren una tensión interna entre los dos extremos (pureza y castidad, por un lado, impureza y corrupción, por el otro), que las suele llevar a experimentar sentimientos negativos contra sí mismas. 
la propia Lady Dunreath, quien, recluida de por vida por su hija — la malvada hermanastra de Malvina - en la abadía, vaga cual espectro por sus galerías abandonadas sin encontrar reposo ni expiación para las maldades cometidas.

La obra de Roche, aun sin acercarse a la corriente del horror más que superficialmente, es un magnífico ejemplo del encuentro entre romance y novel que caracteriza a la literatura escrita por las mujeres a finales del XVIII, superponiendo los valores idealizados — virtud, honor, felicidad-y los finales reconfortantes de la narrativa heroico-romántica sobre un fondo realista, el de las clases acomodadas de la sociedad inglesa del momento.

En realidad, sólo las novelas de Ann Radcliffe ${ }^{36}$ encajan con cierta holgura en el patrón del relato de horror. De las seis novelas que escribió entre 1789 y 1802 , cuatro fueron traducidas al español ${ }^{37}$, aunque no lo hicieron en estricto orden cronológico. La primera que se vierte al español, en 1819, es Julia, o los subterráneos del castillo de Mazzini (traducción de A Sicilian Romance, 1790) seguida en 1821 por El confesonario [sic] de los penitentes negros (The italian, 1797) y en 1830 por Adelina o la abadía en la selva (The Romance of the forest, 1792) ${ }^{38}$. La última que se publica, Los misterios de Udolfo (The mysteries of Udolpho, 1794), lo hace fuera de nuestras fronteras, en París, en 1832.

${ }^{36}$ La popular Ann Radcliffe (1764-1823) escribió seis novelas en el abundante tiempo libre que le dejaba su matrimonio con el ocupado periodista y editor del English Chronicle, William Radcliffe. El éxito le sobrevino, fundamentalmente, tras la publicación de The Mysteries of Udolfo (1794) y de The Italian (1797), adquiriendo una gran reputación como escritora de novela gótica en Inglaterra y en el extranjero. A pesar de su éxito, siempre renunció a incorporarse a la sociedad literaria de su tiempo, y prefirió la vida doméstica con su marido y los viajes juntos, de los que dejó diversos testimonios. La vida privada de Radcliffe, que ella protegió celosamente, es aún hoy un misterio. Desconocidas son, por ejemplo, las razones por las que abandonó la escritura a los treinta y tres años, en la cima de su fama. ¿Fueron, quizás, los derroteros por los que comenzaba a circular el género gótico alrededor del cambio de siglo, con las obras algo sanguinarias y bastante lascivas de Matthew Lewis - The Monk - o Karl Grosse - Horrid Mysteries_, la causa de su repentino abandono?. Lo cierto es que pasó los últimos veinticinco años de su vida recluida en su hogar, escribiendo por placer; a esta etapa pertenecen la novela histórica Gaston de Blondeville y el poema narrativo At. Alban's Abbey. Persistentes rumores acerca de su salud mental corrieron por la Inglaterra de la época, llegando a afirmarse que los excesos de su imaginación la habían conducido a la alienación e incluso a la muerte, aunque esto fue enérgicamente desmentido por su viudo. (MILES, Robert. Ann Radcliffe: The Great Enchantress. Manchester: University Press, 1995, pp. 7-33).

${ }^{37}$ Ver listado final de obras traducidas citadas.

${ }^{38}$ Es evidente que para 1830 la obra de Ann Radcliffe era ya conocida y apreciada en España, ya que Santiago Alvarado de la Peña, traductor de The Romance of the Forest, asî lo hace notar en la portada de su versión: Adelina o la abadía en la selva. Novela histórica escrita en inglés por Mis [sic] Ana de Radcliff, autora de Julia o los subterráneos del Castillo de Mazini y de otras muchas obras (Madrid, 1830). 
Es evidente, a la luz de estos datos, que el éxito cosechado por Radcliffe en su propio país ${ }^{39}$ tiene eco tardío en España, ya que median casi dos décadas entre la primera traducción al español de una de sus novelas (Julia) y el original inglés. No resulta sorprendente, por otro lado, que sea ésta la primera versión de Radcliffe a nuestro idioma, ya que la novela - al igual que la anterior, The Castles of Athlin and Dunbayne, que no fue traducida - todavía se halla lejos, en cuanto a sus procedimientos y a su fondo, del relato de horror, encajando más bien en los cánones de la ficción romántica al uso. Debemos señalar que tanto Julia como Adelina o la abadía en la selva se tradujeron al español sin conflicto y tuvieron diversas ediciones, pues no difieren en demasía de las otras novelas de escritoras inglesas, de aventuras sentimentales y final moral, vertidas en esa misma época.

También coinciden en el desarrollo de la trama - heroínas virtuosas acosadas por villanos en escenarios sobrecogedores-y en su desenlace —resolución del conflicto, reinstauración del orden y de la felicidad- las otras dos obras de la escritora traducidas al español: El confesonario[sic]de los penitentes negros y Los misterios de Udolfo. Y sin embargo, su contenido, bastante más comprometido con la estética y el fondo ideológico del relato gótico, condicionó notablemente las circunstancias de su traducción a nuestro idioma: de hecho, la primera encontró versión española en 1821, es decir, durante el Trienio Liberal, y no se volvió a editar hasta 1832, y en París. Por su parte, Los misterios de Udolfo, sin duda la obra más popular de Radcliffe, nunca se publicó en España y sólo lo hizo en París, el mismo año y en la misma editorial que El confesionario.

Me parece de especial interés, de entre todas las novelas de escritoras inglesas traducidas en España, el caso de El confesonario de los penitentes negros ${ }^{40}$, traducción de The italian (1797), la última de las cuatro obras de Radcliffe vertidas al español que fue publicada en vida de la autora ${ }^{41}$. ¿Por qué los potenciales traductores y editores españoles sólo se atrevieron a sacarla a la luz aprovechando el período constitucional, habiendo sido una novela de tan gran aceptación entre las lectoras inglesas, ya trasladada al

${ }^{39}$ De hecho, aunque no todas las críticas recibidas por su obra fueron positivas, la mayoría de ellas reconocían sin dudas la preeminencia de Radcliffe en el ámbito de la ficción inglesa. Recordemos, a modo de ejemplo, las palabras de Coleridge en el Critical Review de 1798: «In reviewing The Mysteries of Udolfo, we hazarded an opinion, that, if a better production could appear, it must come only from the pen of Mrs. Radcliffe...» (cit. por MILES, op. cit., p. 24).

${ }^{40}$ Existe otra edición de la misma traducción (Málaga: Imprenta y Librería de Andrea Martínez, s.a.), sin duda posterior a 1832, pues recoge en su portada referencia a Radcliffe como autora de Los misterios de Udolfo, obra no trasladada al español hasta esa fecha. Su título es El italiano, o el confesonario de los penitentes negros.

${ }^{41}$ The Italian es también la penúltima que ella escribe. La última, Gaston de Blonville (1802) se publica en inglés póstumamente (1826) y no se traduce al español. 
francés desde hacía decádas ${ }^{42}$, y sabiendo —como sabemos- que Radcliffe era autora bien acogida entre el público español ${ }^{43}$ ?

Recordemos brevemente su contenido. La novela, ambientada en la Italia de fines del XVIII, recoge el conflicto entre el amor y las alianzas matrimoniales, a través de la historia romántica de la huérfana Ellena di Rosalba y el noble Vivaldi, que encuentra una oposición desmedida en el orgullo feudal de la Marquesa, la madre del joven, y en los intereses bastardos de su confesor, el oscuro padre Schedoni. Las maquinaciones de estos dos personajes conducen al encerramiento de Ellena en un convento, a su fuga del mismo y a un nuevo secuestro por parte del villano Schedoni, a lo largo del cual la heroína descubre que él es su supuesto padre. Vivaldi, mientras tanto, falsamente acusado por Schedoni, es conducido a Roma y encerrado en las siniestras mazmorras de la Inquisición, donde, a lo largo del proceso contra el muchacho, se revela dramáticamente que el confesor asesinó a su propio hermano, el auténtico padre de Ellena, y a la madre de ésta para usurpar sus privilegios. Finalmente se descubre que la madre de Ellena vive, convertida en monja para escapar de la maldad de Schedoni, y se consuma el matrimonio de los dos jóvenes.

Lo cierto es que, por debajo de esta trama argumental, que encaja a la perfección en los cánonces de la novela de aventuras sentimentales, El italiano presenta una carga ideológica considerable, ligada a las circunstancias sociales de la Inglaterra del cambio de siglo, pero no por ello menos difícil de encajar en los pilares político-morales de la España fernandina. De hecho, el severo tratamiento de la religión católica y los ataques al pensamiento monárquico-feudal son elementos clave de la propuesta ideológica de esta novela, que está bastante más comprometida de lo que parece con la visión del mundo de la emergente burguesía británica a la que su autora pertenece.

La religión católica está representada en la novela por dos instituciones represoras: el monasterio de San Stefano y la Inquisición de Roma. El primero aparece como una institución hipócrita, jerárquica, tiránica y fundada en una ciega obediencia a un dogma carente de sentido; se le opone en la novela el Convento de la Santa Pieta, que, aunque católico, disfruta

${ }^{42}$ El enciclopedista francés André Morellet traduce The Italian el mismo año de su publicación en inglés.

${ }^{43}$ De hecho, varias traducciones apócrifas circulan por la España de la época, basadas en versiones francesas, también apócrifas. Es el caso, por ejemplo, de Las visiones del castillo de los Pirineos (1828) o El sepulcro (1830). Las traducciones francesas son de 1803 (Londres, G. \& J. Robinson) y 1799 (Paris, Smith) respectivamente.

Cuando en 1830, Santiago Alvarado y de la Peña publica en español The Romance of the Forest, no olvida recordar en la portada de su edición que Ann Radcliffe es «autora de Julia o los Subterráneos del Castillo de Mazini y de otras muchas obras», pero se cuida mucho de nombrar El confesonario de los penitentes negros. 
— gracias a la «ilustración» de su superiora- de unos valores liberales y antidogmáticos, que el lector reconoce inmediatamente como propios de la fe protestante. Por otra parte, los capítulos dedicados a la estancia de Vivaldi en la prisión inquisitorial constituyen un rosario de horrores, subterráneos, torturas, verdugos encapuchados, envenenamientos, etc., que no dejan dudas respecto a las intenciones de la autora. Recordemos que, desde la época del Terror francés, que provocó una intensa reacción al otro lado del Canal, era frecuente en la imaginación de la clase media inglesa asociar los horrores de la Bastilla — que había servido también para encarcelar a Hugonotes y otros herejes - con los de la Inquisición, modelos ambos de una usurpación ilegítima de autoridad, dos caras de una misma pesadilla que incluía la tiranía de la Iglesia y el capricho del Estado como expresiones de un idéntico despotismo. La novela de Radcliffe no esconde esta asociación, y aunque en ella los cargos contra Vivaldi son de naturaleza religiosa, la Inquisición resulta fácilmente identificable con la Bastilla, representando ambos por igual los excesos del feudalismo y los principios del desenfreno monárquico.

Y es que también el sentimiento antimonárquico se presenta en $\mathrm{El}$ italiano sin ambages, a través, fundamentalmente de la Marquesa - madre de Vivaldi- y de su confesor, el malvado Schedoni, que representan distintas facetas del antiguo régimen y defienden sus valores, fundados en los derechos del privilegio. La marquesa, con su acciones y su discurso, ratifica el deseo de un mundo medieval, de rígidas jerarquías y soberanía absolutamente feudal. Schedoni, por su parte, movido por intereses bastardos, apoya las pretensiones de la Marquesa, pero al mismo tiempo introduce en la novela el relativismo moral, con un discurso de libertinaje filosófico reminiscente del de los librepensadores blasfemos del Marqués De Sade. El oscuro confesor defiende la moral natural, dejando entrever que costumbre y ley no son más que vulgares prejuicios, y afirmando un mundo moralmente anárquico, de autoaserción y poder.

El pacto de ambos personajes revela de forma bastante obvia que, en la reconstrucción hecha por Radcliffe del pasado continental, libertinaje filosófico y antiguo régimen forman una alianza cuya inmoralidad aparece ligada a la inestabilidad social del presente. Por otra parte, frente a la exigencia de los derechos del privilegio encarnada por Schedoni y la Marquesa, El italiano afirma taxativamente la inviolabilidad de los derechos humanos a través de la pareja opuesta, la que forman los inteligentes, virtuosos y sensibles Ellena y Vivaldi. Los dos representan en la novela la fuerza de una clase media, entre la corrupción aristocrática de la Marquesa y el estrato ocupado por criados y campesinos, cuya condición fundamental es la sensibilidad, a través de la cual se expresan como seres humanos. La novela refleja en este sentido las tensiones sociales de la Inglaterra del momento, entre una burguesía «liberal», que enarbolaba unas nuevas no- 
ciones de moralidad y propiedad, y una vieja élite, percibida como lujuriosa, superficial, inmoral y retrógrada; Ellena di Rosalba y su madre, Olivia, despojadas de sus derechos básicos por esa aristocracia recalcitrante, son el mejor ejemplo de dichas tensiones y de los peligros inherentes.

La ideología de la novela de Radcliffe está en perfecta consonancia con esa cultura de la clase media provinciana inglesa que creía en las virtudes democratizadoras de la sensibilidad, pero que en el fondo no dejaba de ver en ella una cualidad íntrinsecamente burguesa. La relación amorosa de Ellena y Vivaldi, conducida siempre a través del lenguaje de los derechos humanos, y el ideal de matrimonio burgués, sustentado en el compañerismo y el respeto, en el que aquélla se consolida al final de la obra, constituyen el mejor ejemplo de esa sensibilidad burguesa y de sus beneficiosos efectos sobre la felicicidad de los individuos.

No es difícil colegir, con lo dicho hasta el momento, la escasa adecuación del mensaje de esta novela a la ideología de la España de Fernando VII, nada dispuesta a tolerar envites de signo progresista contra sus pilares fundamentales, catolicismo y aristocracia, o a admitir libelos antimonárquicos, menos aún de manos femeninas, que no por ser blancas tenían menor capacidad de ofensa o de transgresión. De hecho, la limitada participación de las mujeres españolas en la narrativa — fundamentalmente a través de la traducción - no permitía hasta el momento otras consignas que las destinadas a reforzar las funciones sociosexuales para ellas establecidas, de manera que el atrevimiento de Radcliffe al tratar en su novela temas poco habituales en la pluma femenina sólo podía ser tolerado en nuestro país en un momento de agitación ideológica que justificase su excepcionalidad. No sorprende pues, si a ello sumamos los ataques a la Inquisición que la novela contiene, que su traducción al español se publicara precisamente en pleno período constitucional, aprovechando la supresión temporal de la Suprema por los hombres del Trienio Liberal ${ }^{44}$, y que pasara después la Década Ominosa durmiendo el sueño de los justos, como tantas otras obras extranjeras y nacionales de escasa ortodoxia ideológica.

Aunque estas páginas no constituyen más que una primera aproximación a la recepción de la obra de las escritoras inglesas en la España del primer tercio del XIX, que lamentablemente no ha despertado, hasta el momento, gran atención crítica, nos permite al menos comprobar que la novela escrita por mujeres que llega a nuestro país en esa época es, a pesar de sus pocos ejemplos, variada, y no siempre tan inocua como se pretende

${ }^{44}$ Como bien señala GARCÍA CASTAÑEDA, Salvador, en «La Inquisición, tema literario de la novela de la emigración (1800-1837)» [en lwww.cervantesvirtual.com), la mayoría de los libros publicados en español sobre la Inquisición en tiempos de Fernando VII, se edita fuera de España o aprovechando períodos concretos, como el de las Cortes de Cádiz o el Trienio Liberal. Sólo una mínima parte corresponde a libros de ficción, y casi todos son traducciones de novelas góticas inglesas o alemanas. 
cuando se habla de narrativa femenina dieciochesca, generalmente asociada a la intrascendencia sentimental y al didactismo fácil. Ninguna duda cabe de que, de las obras educativas de Helme, Opie o Bennet, a las más comprometidas y transgresoras de Lee o Radcliffe hay no poca distancia, pero lo importante es que todas tuvieron cabida en la España de las primeras décadas del XIX. Su presencia revela una elección previa de los textos por parte de sus traductores, la cual responde a su vez a una demanda social concreta, la de un público de signo burgués y cada vez más femenino, deseoso de consumir las lecturas que entretenían a la clase media europea de su tiempo. Sin duda, aunque la escritura femenina no acabara aún de encontrar unas vías de expresión propia en la literatura nacional, interesaba - y no poco- lo que escribían las mujeres, tanto en el camino más trillado de lo didáctico-sentimental como en el más novedoso de la narrativa gótica, que tampoco cuaja en la literatura española de principios del XIX, pero que sin duda abre los caminos para la posterior revolución romántica.

\section{TRADUCCIONES DE OBRAS INGLESAS CITADAS EN EL TEXTO}

BENNET, Agnes. Ana o la heredera del país de Gales. Enciso Castrillón, Félix (trad.). Madrid: Repullés, 1818-1819.

—. Rosa o la niña mendiga y sus bienhechores. Enciso Castrillón, Félix (trad.). Madrid: Repullés, 1819-1820.

- Colección de obras completas de Mistress Bennett. Madrid: Escamilla, s.a.

HELME, Elizabeth. Luisa o la cabaña en el valle. Salamanca: Toxar, 1797.

- Alberto el desierto de Strathnavern. Madrid: Imprenta calle de la Greda, 1807.

-. Saint-Clair de las Islas o los desterrados de la isla. Barcelona: Gorchs, 1828.

-. El peregrino o Cristabela de Mowbray. Madrid, 1832.

LEE, Harriet. Cuentos de Canterbury. Madrid: Imprenta de la Vega, 1808.

LEE, Sophia. El subterráneo o la Matilde. Madrid: Imprenta de la Viuda e hijo de Marn, 1795.

—. El subterráneo o las dos hermanas, Matilde y Leonor. Madrid: Villalpando, 1817.

LENNOX, Charlotte. Don Quijote con faldas o Perjuicios morales de las disparatadas novelas. Calzada, Benardo María de la (ed.). Madrid: Fuentenebro, 1808.

OPIE, Amelia. El padre y la hija. Barrera, Juana (trad.). Madrid: Dávila, 1820.

RADCLIFFE, Ann. Julia, o los subterráneos del castillo de Mazzini. Valencia: Cabrerizo, 1819.

—. El confesonario de los penitentes negros. Madrid: Brugada, 1821.

- Adelina o la abadía en la selva. Madrid: Sancha, 1830.

- Los misterios de Udolfo. París: Pillet, 1832.

ROCHE, Regina María. Los niños de la Abadia. Madrid: Imprenta de la Vega, 1808.

- Oscar y Amanda, o los descendientes de la abadía. Melcior, José (trad.). Barcelona: Juan Dorca, 1818-1820.

Fecha de recepción: 29 de mayo de 2009

Fecha de aceptación: 10 de diciembre de 2009 